\title{
MIGRACIÓN CENTROAMERICANA EN TRÁNSITO POR MÉXICO: SU TRATAMIENTO EN EL ACTUAL MARCO NORMATIVO MIGRATORIO
}

\author{
JUANA LUISA RÍOS-ZAMUDIO*
}

\section{RESUMEN:}

En el presente trabajo se sostiene que dos de los principales factores que llevaron a la adopción de la ley de migración en 2011 fueron, por un lado, la creciente migración irregular en su modalidad de migración en tránsito y los problemas de violencia que en torno a ella se desarrollaron y, por el otro, las numerosas recomendaciones elaboradas por diversos organismos internacionales de derechos humanos. Se explica cómo en relación a estos dos elementos, la ley de migración no ha cumplido de forma satisfactoria el objetivo para la cual fue creada, esto es, ser un marco garante de los derechos humanos de los migrantes irregulares.

\section{Palabras Clave:}

Ley de migración, migración indocumentada o irregular en tránsito, organismos internacionales de derechos humanos, migración centroamericana

\section{ABSTRACT:}

In the present work, it is argued that two of the main factors that led to the adoption of the migration law in 2011 were, on the one hand, the growing irregular migration in its form of transit migration and the problems of violence that surround it and, on the other, the numerous recommendations prepared by various international human rights organizations. It is explained how in relation to these two elements, the migration law has not satisfactorily fulfilled the objective for which it was created, that is, to be a framework that guarantees the human rights of irregular migrants.

* Universidad Veracruzana. Correo: j1_rioszam@yahoo.com.mx 


\section{Keywords:}

Immigration Act, undocumented or irregular transit migration, international bodies protecting human rights, Central American migrantion

\section{INTRODUCCIÓN}

El 25 de mayo de 2011 se publicó en el Diario Oficial de la federación la actual ley de migración, que sustituyó en la parte conducente a la ley general de población de 1974, la cual había sido objeto de múltiples señalamientos en el sentido de que ya no respondía a las exigencias de la realidad migratoria de México. Esta nueva ley fue el resultado de un largo proceso en el que diversas fuerzas políticas, pero sobre todo multitud de organizaciones nacionales y organismos internacionales, presionaron al Estado mexicano para que adecuara la legislación relativa a los compromisos internacionales asumidos en materia de migración y derechos humanos.

Aunque en materia migratoria México es ya un país de origen, tránsito, retorno y destino, en el presente trabajo se parte de la consideración de que la ley de migración fue motivada sobre todo como un medio para atender la creciente migración irregular registrada en México en los últimos años, en particular lo que se conoce como migración en tránsito, así como por los reclamos que ha recibido el Estado Mexicano en este rubro, principalmente por parte de los organizaciones defensoras de los derechos humanos; también se afirma que la ley fue una respuesta a las recomendaciones planteadas a México por parte de los organismos internacionales de derechos humanos de los sistemas universal e interamericano. Lo anterior sostiene en razón de que en México los flujos migratorios regulares han estado compuestos por personas que al ser consideradas "gratas o deseables", el propio Estado mexicano se ha asegurado de brindarles las condiciones necesarias para una estancia agradable y productiva. ${ }^{1}$ Además, los reclamos y demandas de los migrantes mexicanos (los residentes en el extranjero, principalmente en los Estados Unidos, y el cada vez mayor número de retornados), como el de facilitarles el ejercicio de derechos sociales y político-electorales tanto en el extranjero como en su regreso a México, así como el reconocerles su contribución a la economía nacional por motivo de las remesas que envían a sus familias y comunidades, entre muchos otros, si bien son numerosos y se encuentran fundamentados, tradicionalmente han sido gestionados a partir de otros instrumentos y vías que en su momento no significaran o no se tradujeron en la adopción de una ley de migración.

En este sentido, en el presente trabajo se explica por qué dos de los principales factores que llevaron a la creación de ley de migración fueron, primero, la copiosa migración indocumentada, principalmente en la modalidad de migración en tránsito, así como la grave violencia que se generó en torno suyo; $\mathrm{y}$, en segundo

Históricamente, al menos a lo largo del siglo XX, el Estado mexicano fomentó la migración de campesinos de origen europeo, así como de trabajadores especializados, profesionistas, intelectuales, pensionistas, empresarios e inversionistas, principalmente provenientes de países desarrollados. 
lugar, la presión ejercida principalmente por organismos internacionales de derechos humanos, los cuales emitieron durante una década rigurosos informes señalando la escasa disposición del Estado mexicano para atender a los migrantes en tránsito, garantizarles derechos mínimos y ajustar la legislación correspondiente a los estándares internacionales. Los dos primeros apartados de este artículo se dedican a esta tarea. ${ }^{2}$

Posteriormente, en un tercer apartado se explica cómo a pesar de que la ley de migración incorpora muchas de las exigencias de los organismos internacionales, se mantienen en ella elementos que resultan restrictivos de los derechos de los migrantes; con lo cual, se queda lejos de satisfacer el objetivo que el Estado mexicano argumentó perseguir con su elaboración, esto es, crear un marco jurídico que propiciara no sólo una mejor gestión de los flujos migratorios que tienen lugar en este país sino, sobre todo, un marco garante de los derechos de las personas migrantes. Para finalizar, en una cuarta sección se explica por qué el periodo gubernamental que ahora concluye, pese a que inició con un nuevo marco regulatorio de la migración que representaba la posibilidad de instrumentar una gestión o "gobernanza migratoria" más respetuosa de los derechos humanos de las personas migrantes, tal oportunidad se dejó pasar, pues como se verá lo que en realidad se vivió fueron seis años de acciones reactivas y desarticuladas a la usanza de los gobiernos anteriores.

\section{MIGRACIÓN INDOCUMENTADA Y VIOLENCIA EN MÉXICO: EL CONTEXTO QUE OBLIGA A UNA ACTUALIZACIÓN NORMATIVA}

Aunque todo el siglo XX el territorio mexicano fue ocupado como corredor para extranjeros de diversas nacionalidades que buscaban adentrarse en Estados Unidos tanto de manera regular como irregular, ${ }^{3}$ el flujo de migrantes en tránsito se hizo más visible hacia finales de la década de los ochenta. En ese entonces el grupo más numeroso y conocido en la frontera sur de México era el de personas que buscaban refugio de los conflictos bélicos que afectaban la región centroamericana, provenientes sobre todo de las áreas rurales de Guatemala. No obstante, los flujos de migrantes en tránsito, originarios no sólo de Guatemala sino también de Honduras y El Salvador, no pasaron desapercibidos; los estudia Rodolfo Casillas desde 1991, cuando además de dar explicar su dinámica migratoria, señala también varios de los problemas a los que desde entonces se enfrentaban en su ingreso y durante su recorrido por el territorio mexicano.

Los registros oficiales permiten apreciar la existencia de flujos de migrantes indocumentados en tránsito desde la década de 1970 y su exponencial incremento en 1990, cuando se realizaron 126,440 eventos de aseguramiento, mientras que

\footnotetext{
2 Vale la pena hacer la aclaración que es por este motivo que en el presente trabajo se utilizan datos previos a la adopción de la ley de migración.

3 Así lo explica PABLO YANKELEVICH, ¿Deseables o indeseables? Las fronteras de la extranjería en el México posrevolucionario, Bonilla Artigas Editores, México, 2011.
} 
apenas el año anterior, en 1989 se habían llevado a cabo sólo 518 eventos, y la cifra máxima en años previos no había superado los $15,000 .{ }^{4}$ En lo que va del presente siglo, los datos más significativos son el de 2005 y el de 2011, cuando se registran el más elevado y el más bajo número de aseguramientos, respectivamente (Tabla 1.1). El incremento de los aseguramientos en más de un 56\% durante el quinquenio 2000 a 2005 es referido por algunos autores como correlativo del incremento en el número de personas que cruzan la frontera sur de México en situación irregular. ${ }^{5}$ Otros, consideran que las adversas condiciones luego de los huracanes Mitch (1998) y Stan (2004) y las secuelas económicas que dejaron para los habitantes de la región, fueron detonantes para que se incrementara el flujo y, por lo tanto, los aseguramientos $;{ }^{6}$ aunque habría de considerar también el constante incremento en los niveles de violencia que afectan al ciudadano común en estos países, punto en el que si bien no ahondamos aquí, sí es necesario tener presente. Otros autores consideran que dichos eventos de aseguramiento corresponden más bien a la política de endurecimiento hacia la migración, la cual México asumió por presiones del gobierno estadounidense luego de los atentados terroristas del 11 de septiembre de 2001 en ese país, lo que coincide con los cambios e inversiones en infraestructura y en personal que duplica el número de estaciones migratorias tan sólo en ese periodo; esto es, que para algunos no fue el flujo el que incrementó propiamente, sino los operativos de retención. ${ }^{7}$

4 MANUEL ÁNGEL CASTILLO, "Las políticas hacia la migración centroamericana en países de origen, de destino y de tránsito", Revista Papeles de población, Vol. 6, no. 24, abril-junio, UAEM, México, 2000, p. 174.

5 ERNESTO RODRÍGUEZ CHÁVEZ; SALVADOR BERUMEN SANDOVAL y LUIS FELIPE RAMOS, "Migración centroamericana de tránsito irregular por México. Estimaciones y características generales", Apuntes sobre migración, no. 2, Centro de Estudios Migratorios del INM, México, 2011, pp. 12.

6 Armijo, Benítez y Hristroulas señalan que la devastación de ciudades, pueblos y campos de cultivo por el paso del huracán trajo como consecuencia el desempleo y la desesperación que condujo a muchos jóvenes no sólo a migrar, sino también a vincularse con las pandillas salvadoreñas, lo que se suma a los factores analizados en el capítulo anterior respecto de los incrementos en la violencia en la región; en NATALIA ARMIJO CANTO; RAÚL BENÍTEZ MANAUT y ATHANASIOS HRISTOULAS "Las maras en triángulo de seguridad Centroamérica-México-Estados Unidos", en Carlos Barrachina (coord.), Democracias en transición en Honduras y Nicaragua. Gobernabilidad, seguridad y defensa, Universidad de Quintana Roo-Plaza y Valdés, México, 2010, págs. 340-344.

7 LUIS HERRERA-LASSO y JUAN B. ARTOLA, "Migración y seguridad: dilemas e interrogantes" en Natalia Armijo, Migración y seguridad: nuevo desafio en México, CASEDE, México, 2011, p. 16. 


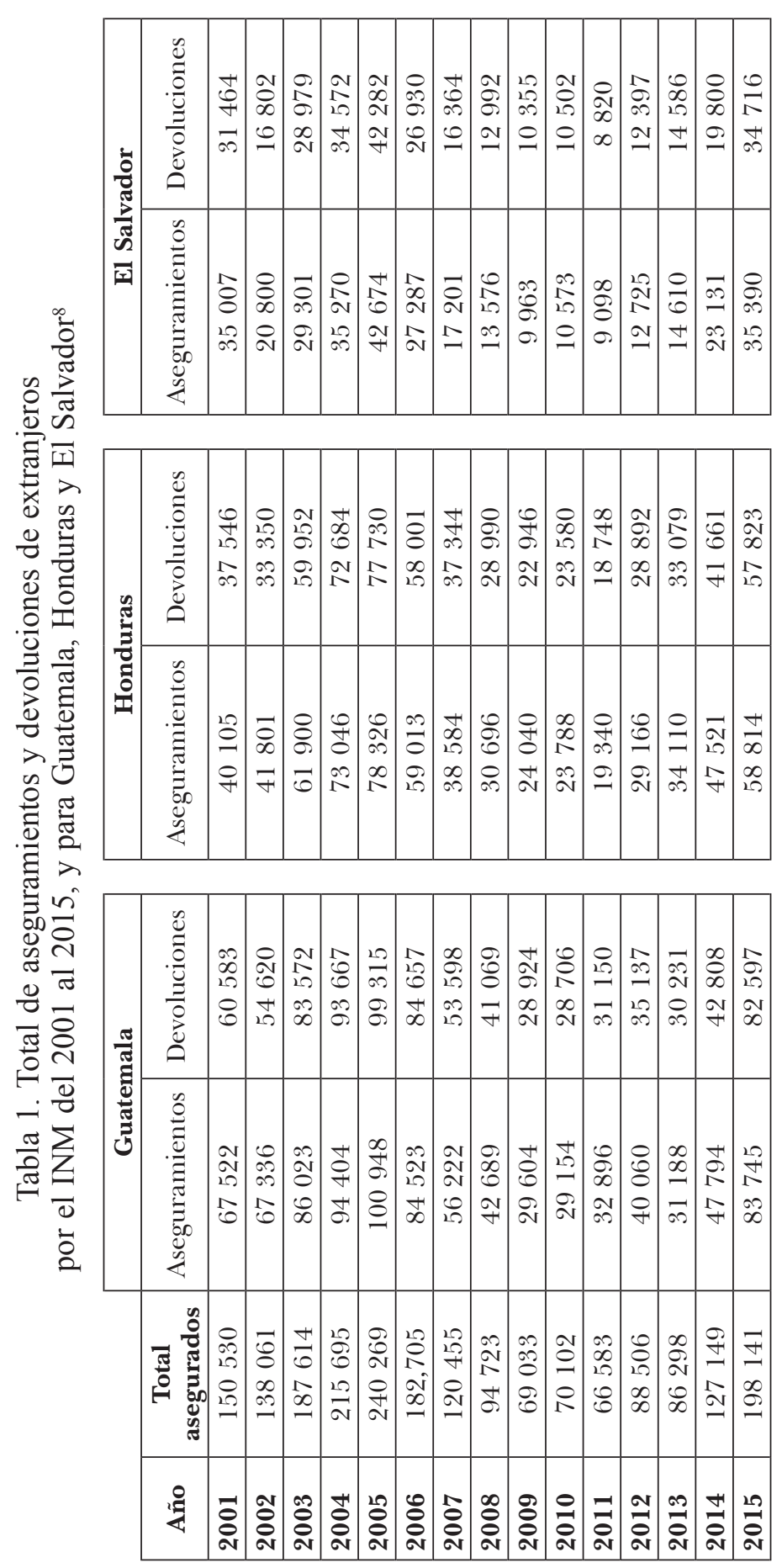


Respecto del relativo descenso que se observa entre 2008 y 2013 la interpretación más aceptada señala que el endurecimiento de los operativos de retención por las rutas ya conocidas por los migrantes, obligó a estos a trazar otras nuevas. Estas nuevas rutas resultaron ser en ocasiones no sólo más largas, sino también más peligrosas al quedar los viajeros lejos de los ojos de las autoridades pero expuestos a los de la delincuencia..$^{9}$ Otros autores, por el contrario, señalan un relajamiento en tales operativos por parte del Instituto Nacional de Migración (INM) que llevó a una disminución en el número de asegurados. ${ }^{10}$ También se ha dicho que el incremento en las deportaciones de migrantes desde Estados Unidos hacia la región, así como la crisis financiera en ese país que afectó las principales industrias en las que suelen emplearse los migrantes indocumentados, pudieran haber sido factores que desmotivaran a los migrantes, llevando así a la reducción de los flujos en tales momentos. ${ }^{11}$

Es importante señalar que se habla aquí de disminución relativa ya que en realidad no se puede decir cuántos cruces por ambas fronteras sean exitosos o no, y tampoco determinar cuántos de estos viajeros interrumpen su travesía asentándose en México de manera provisional, aunque después se pueda transformar en definitiva. Por su parte, el considerable incremento que volvió a tener el número de asegurados para 2014, es explicado por la mayoría de los autores como efecto del Plan Frontera Sur implementado un año antes, pues como hemos de ver más adelante, las acciones del plan estuvieron más enfocadas al aseguramiento de personas migrantes en dicha frontera, que a brindar atención a su persona y proteger sus derechos.

Para los primeros años del presente siglo, la situación de los migrantes centroamericanos en tránsito se puede conocer a través de los trabajos de Olivia Ruiz Marrujo. ${ }^{12}$ Esta autora señaló que delitos tales como el robo, la estafa, la violación y el secuestro se perpetraban de manera "habitual" hacia los migrantes en la frontera sur de Chiapas. "La trata de mujeres y menores en esa región es un negocio nutrido de la migración centroamericana", apuntaba. Identificó como responsables de estos delitos a pequeñas bandas delictivas y maras que entonces

9 MARÍA DEL CARMEN GARCÍA AGUILAR, "Violencia y ética. A propósito de la inmigración irregular y los derechos humanos en la frontera sur de México", DA GLORIA MARRONI, MARÍA, "Latinoamérica en la geografía mundial: nuestro sur en el norte", y VILLAFUERTE SOLÍS, DANIEL, "Políticas de seguridad y migración transnacional en la frontera sur de México", los tres en Daniel Villafuerte Solís y María del Carmen García Aguilar (coordinadores), Migración, seguridad, violencia y derechos humanos. Lecturas desde el sur, Miguel Ángel Porrúa, México, pp. 90-95; 55-64 y 188 y 189, respectivamente.

10 CARLOS BARRACHINA; JIMMY RAMOS y ALEJANDRO MONJARAZ, "Quintana Roo en el contexto migratorio mexicano" en Enrique Baltar, María da Gloria Marroni y Daniel Villafuerte (coords.), Viejas y nuevas migraciones forzadas en el sur de México, Centroamérica y el Caribe, UQROO, México, pp. 269-314.

11 DANIEL VILLAFUERTE SOLÍS, "Políticas de seguridad y migración trasnacional en la frontera sur de México", en Daniel Villafuerte y María del Carmen García, Migración, seguridad y derechos humanos. Lecturas desde el Sur, México, Porrúa, pp. 180 y 181.

12 OLIVIA RUIZ MARRUJO, "Riesgo, migración y espacios fronterizos, una reflexión”, Estudios demográficos y urbanos, v. 16, no. 2 (47), mayo-junio, El Colegio de México, México, 2001 y "Los riesgos de cruzar. La migración centroamericana en la frontera México-Guatemala”, Frontera Norte, vol. 13, no. 25, enero-junio, El Colegio de la Frontera Norte, México, 2001. 
operaban de manera desarticulada en ambos lados de la frontera. El trabajo de esta autora permite conocer una visión ya no sólo de abuso hacia los migrantes en la frontera sur, sino propiamente de violencia, de víctimas de delitos, mucho antes incluso de que se empezara a documentar este problema que hoy acontece en buena parte del territorio mexicano por donde se desplaza este flujo. Sus resultados dejan ver la evolución de los grupos delictivos, pues las pequeñas bandas o maras se transformaron en complejos grupos altamente organizados, con una jerarquía y distribución de funciones y territorios de operación bien delimitados, esto, principalmente, al fusionarse con los grupos dedicados al narcotráfico. Es hacia 2007 cuando la situación de violencia hacia los migrantes comienza a visibilizarse y hacerse evidente más allá de la frontera sur.

En diciembre de 2006, Alejandro Solalinde, presbítero encargado del Albergue Hermanos en el Camino, en Ciudad Ixtepec, Oaxaca, denunció el secuestro de seis migrantes centroamericanos ocurrido en las inmediaciones del albergue. Aunque su denuncia no fue atendida propiamente por las autoridades ministeriales, la insistencia del sacerdote hizo que los medios mantuvieran la noticia vigente durante varios días. Cual quien abriera la caja de Pandora, la prensa comenzó a dar cuenta cada vez con mayor asiduidad de cómo el secuestro masivo de migrantes se estaba reproduciendo también en otras partes del territorio nacional.

La reacción de las autoridades de los tres niveles de gobierno fue sistemática en el sentido de negar que tales hechos se estuvieran desarrollando en sus respectivas jurisdicciones. No obstante, las voces de los defensores de derechos humanos no se acallaron y, trabajando de la mano con la Comisión Nacional de los Derechos Humanos (CNDH), ésta dio a conocer en 2009 el Informe Especial sobre los Casos de Secuestros en Contra de Migrantes, el cual arrojó datos alarmantes al respecto, señalando como responsables de la violencia hacia las personas migrantes en tránsito a los grupos delictivos, pero también a las autoridades migratorias y de defensa, así como a las de seguridad de los tres niveles de gobierno. En este informe, la CNDH señala que durante el periodo de documentación del estudio (de septiembre de 2008 a febrero de 2009) se registraron 198 casos de secuestro cuyo carácter masivo daba lugar a un total de 9758 personas migrantes secuestradas, lo que en términos numéricos es un aproximado de 1600 secuestrados por mes o si se prefiere, 50 secuestrados por día.

Los datos del Informe fueron negados y desestimados por el Gobierno de la República argumentando falta de rigor metodológico y sobreestimación de los testimonios recabados; no obstante, la masacre de 72 migrantes indocumentados en el Ejido El Huizachal en el municipio de San Fernando, Tamaulipas reforzaría lo dado a conocer por la CNDH constituyendo prueba fehaciente de las dimensiones que este nuevo modus de violencia había alcanzado dado lo rentable que resultó, no sólo por las ganancias obtenidas a través del cobro de los rescates, sino también, ante la impunidad que privilegiaba a los delincuentes. Pocos días después de estos hechos los medios de comunicación comenzaron a informar de la repetida aparición de fosas clandestinas en esa misma entidad. En abril de 2011, la 
Procuradora General de la República informó que habían sido encontradas, también en Tamaulipas, 49 fosas de la misma naturaleza con un total de 193 cadáveres; ese mismo año, el hecho se replicó en Durango, donde fue localizada una fosa con 186 cadáveres de migrantes. ${ }^{13}$

Dadas las observaciones que se hicieran al Informe de la CNDH, ésta decide elaborar una segunda investigación donde documenta con mayor rigor los testimonio de personas migrantes en el periodo comprendido de abril a septiembre de 2010. En este segundo documento dado a conocer en febrero 2011, la CNDH no sólo corrobora los datos presentados en el primero, sino que incluso registra un alza en el número de secuestros, pasando así en términos generales de 53 personas migrantes secuestradas por día a un aproximado de 60; con todo, es probable que los secuestrados fueran más numerosos, ya que en términos generales el número de delitos de que los se tiene conocimiento suele quedar muy por debajo respecto del número real, lo que suele denominarse cifra negra. Todo esto hizo insostenible la negación del Estado respecto de los niveles de violencia que afectaba a los migrantes en tránsito, la cual ya había sido planteada por algunos organismos internacionales de derechos humanos como problema estructural y de urgente atención.

\section{EL IMPULSO DE ACTORES INTERNACIONALES PARA EL CAMBIO NORMATIVO EN MATERIA MIGRATORIA}

En el estudio de los cambios normativos en materia migratoria es necesario tener presentes las recomendaciones hechas a México por organismos internaciones de derechos humanos. ${ }^{14}$ Desde el año 2000 y hasta antes de la promulgación de la ley de migración en 2011, México recibió siete de estos informes con recomendaciones puntuales en la materia; uno por parte de la Organización de Estados Americanos, y seis más por parte de Naciones Unidas (véase tabla 2).

Desde el primer informe de 2002 de la entonces Relatora Especial sobre los Derechos Humanos de los Migrantes, Gabriela Rodríguez Pizarro (1999-2005), se señalaron al Estado mexicano las condiciones de violencia y vulnerabilidad que en su territorio padecía este grupo. Se destaca la situación de las mujeres y los menores como sujetos constantes o potenciales víctimas de trata; se habla también del agravamiento de estos problemas en la frontera sur, donde la convergencia de bandas delictivas y la corrupción de diversas instancias gubernamentales, estaban

13 Un año más tarde, en 2012, el Movimiento Migrante Mesoamericano reportaba un estimado de entre 20 mil y 70 mil personas migrantes desaparecidas en México.

14 En la década que inicia en el año 2000 se recibieron varias visitas oficiales de estos organismos tanto del sistema universal como del interamericano, a través de las cuales se evaluaron las condiciones de los derechos humanos en nuestro país. Derivado de ello, se empezaron a recibir los respectivos informes con un número considerable de recomendaciones para hacer frente a los problemas que se le señalaron y dar cumplimiento a los compromisos internacionales adquiridos. Hernández Valencia y Anaya Muñoz contabilizan que, entre 1994 y 2013, México recibió un total de 1,885 recomendaciones de tales organismos; esto en JAVIER HERNÁNDEZ VALENCIA Y ALEJANDRO ANAYA MUÑOZ (compiladores), "Introducción”, Recomendaciones internacionales a México en materia de derechos humanos. Contrastes con la situación del país, ACNUM, México, p. 7. 
dando ya lugar a un incremento de los abusos hacia los migrantes, y se señala la impunidad hacia sus perpetradores. Por ello, se insta a México a crear los mecanismos adecuados y realizar las investigaciones necesarias para acabar con la impunidad y la corrupción de este tipo de conductas que lesionan la persona y derechos de los migrantes.

Por su parte, en el Diagnóstico sobre la Situación de los Derechos Humanos en México de 2003 y en el informe de 2006 del Comité de Protección de los Derechos de Todos los Trabajadores Migratorios, ambos de Naciones Unidas, se recomendó garantizar a las personas migrantes el derecho de acceso a la justicia para que su ejercicio no se viera limitado por su condición migratoria, tanto en el ámbito de la procuración, como en el de la administración de justicia. Se sugirió además la creación de una Procuraduría de Atención y Defensa a Migrantes, y se exhortó al Gobierno mexicano a simplificar los procedimientos del Instituto $\mathrm{Na}$ cional de Migración para que los migrantes pudieran reportar los abusos de que fueren objeto y dar seguimiento a los procesos iniciados contra delincuentes o autoridades que violen la ley; se instó también a eliminar los tipos penales que entonces criminalizaban a los migrantes indocumentados para que dicha condición fuera una falta administrativa y no un delito.

Esta última recomendación es hecha también por la Relatoría Especial sobre derechos de los Trabajadores Migratorios y Miembros de sus Familias de la Organización de Estados Americanos en su visita in loco (2003), quien además exhorta a que ya no se exija a los migrantes que acrediten su legal estancia para brindarles protección, pues dicha práctica los coloca a las personas en estado de indefensión, por lo que la recomendación fue reformar el entonces artículo 67 de la ley general de población que en esos momentos exigía, en efecto, comprobar legal estancia para recibir protección legal. No obstante, fue necesario el exponencial incremento en la violencia hacia los migrantes, para que tal recomendación fuera considerada y el artículo señalado fuera modificado en 2008.

Hacia 2009 fue presentado el segundo informe de la Relatoría Especial de Naciones Unidas sobre la situación de los derechos de los migrantes en México. ${ }^{15}$ En su informe, el Relator Especial, Jorge Bustamante, expresó su preocupación por la situación de las personas migrantes en varios rubros: las trabajadoras domésticas, los menores migrantes no acompañados y trabajadores, las víctimas de tráfico y trata, la escasez de asistencia consular con la que cuentan los migrantes, las condiciones en las que se llevan a cabo los aseguramientos, el alojamiento y la repatriación, así como la colusión de autoridades de los tres niveles de gobierno

15 Para ese momento, debe recordarse, las manifestaciones de violencia hacia los migrantes en tránsito se habían extendido más allá de la frontera sur, alcanzando varias de las entidades federativas que quedaban en el paso de las rutas tomadas por los viajeros y el secuestro masivo era la expresión más denunciada de la violencia hacia los migrantes. La situación había empeorado al punto que ese mismo año, a sólo unos meses después del Informe del Relator Especial, la Comisión Nacional de los Derechos Humanos presentaría también su Primer Informe sobre casos de secuestro en contra de migrantes en México con las dramáticas cifras que ya se han comentado. El contexto dio lugar a rigurosas recomendaciones a México en la materia, pudiendo considerarse hasta ahora este segundo Informe de la Relatoría Especial como el más severo de los remitidos a México. 
con bandas y grupos delictivos. El Relator recomendó, entre otros aspectos, introducir las reformas legislativas adecuadas contra la impunidad por las violaciones de derechos humanos hacia los migrantes, ya que, desde su perspectiva, ahí radican algunas de las principales deficiencias del sistema judicial; este es un punto importante aunque hay que diferenciar entre la violaciones a derechos humanos que atienden las comisiones de derechos humanos, y los aspectos operativos que hacen ineficiente el sistema de procuración de justicia en México.

Por su parte, con la creación del Consejo de Derechos Humanos de Naciones Unidas en marzo de 2006 (en sustitución de la Comisión de Derechos Humanos del mismo órgano), se instruyó un nuevo mecanismo denominado Examen Periódico Universal (EPU), a través del cual se sondea la situación de los derechos humanos de los Estados miembros. ${ }^{16}$ En las recomendaciones del EPU 2009 los temas prevalecientes fueron la violencia hacia las mujeres y el acceso a la justicia para personas miembros de los pueblos indígenas, aunque también es posible localizar algunas recomendaciones en el tópico que aquí se aborda.

Uzbekistan, por ejemplo, encaminó su recomendación a sugerir al Estado mexicano la adopción de medidas para proteger los derechos de los trabajadores migrantes y sus familias, garantizando de manera particular el acceso a la justicia, esto ante las dificultades de los migrantes para acceder a las instituciones de justicia cuando son expulsados de México, según los informes de Naciones Unidas. En el mismo sentido se pronunció Guatemala, quien instó a México acerca de la importancia de que los migrantes tengan acceso a recursos judiciales efectivos ante una autoridad competente para la protección de sus derechos; este Estado recomendó también enjuiciar y sancionar a los funcionarios públicos responsables de malos tratos y delitos cometidos contra este grupo. Las recomendaciones de Guatemala deben leerse como parte de la preocupación hacia sus connacionales migrantes quienes, como se ha revisado en el capítulo anterior, junto con las personas provenientes de Honduras y El Salvador, conforman arriba del 85\% de la migración indocumentada en tránsito por México.

Para 2011 el Comité de la Protección de los Derechos de Todos los Trabajadores Migratorios y de sus Familiares de Naciones Unidas presentó el Examen al Segundo Informe Periódico Presentado por México. ${ }^{17}$ En general es un documento bastante corto, pero plagado de recomendaciones para mejorar la situación

$\overline{16}$ En el EPU, 47 de los Estados miembros se integran como grupo de trabajo y pueden realizar preguntas, observaciones y recomendaciones al Estado que está siendo evaluado respecto del cumplimiento de sus compromisos internacionales asumidos en materia de derechos humanos. Estas recomendaciones se dan en función de las respuestas dadas por el Estado evaluado a las preguntas que previamente le hayan sido planteadas por los integrantes del grupo de trabajo. Lo interesante de este procedimiento es que en realidad se promueve un diálogo en materia de derechos humanos entre los Estados; así también, se puede decir que genera una mayor presión política al Estado evaluado para mejorar sus actuaciones en las materias y rubros que le hayan sido cuestionados por sus pares, considerando que el grupo de trabajo está integrado por cerca de un tercio de representantes de toda la comunidad internacional. México cuenta ya con tres documentos de esta naturaleza: un primer Informe del Grupo de Trabajo sobre el Examen Periódico Universal en 2009 (EPU-2009), un segundo Informe en 2013 (EPU -2013), y el tercer informe que deberá enviarse a México este año 2018.

17 Este segundo examen periódico fue presentado por México el 14 de enero de 2010. 
de los diversos grupos de migrantes en territorio mexicano. Sugiere así, mayor coordinación entre las autoridades de los tres niveles de gobierno para asegurar se respeten sus derechos humanos. Además, el Comité identificó que subsiste un desconocimiento más o menos generalizado de la Convención sobre los derechos humanos de todos los trabajadores migrantes y sus familias, por lo que recomendó a México continuar con las capacitaciones para darla a conocer a las autoridades. Esta recomendación es importante toda vez que en ella se menciona a los diferentes funcionarios que trabajan en la protección de los derechos de los migrantes, no sólo las autoridades migratorias, y se enfatiza la importancia que tiene el que fiscales, jueces, magistrados y personal de la administración de justicia, conozcan el contenido de la Convención para generar mayor comprensión y respeto por los derechos de los migrantes. El Comité también exhorta a México para que instrumente las medidas necesarias a fin de garantizar que las personas migrantes cuyos derechos hayan sido violentados tengan acceso a recursos eficaces y a una reparación adecuada. En este punto se destaca la relevancia de atender a aquellas personas que enfrentan graves violaciones a sus derechos humanos y son víctimas de diversos delitos en México, como abusos sexuales, secuestros y trata. Se resalta lo importante de realizar investigaciones y diligencias serias para sancionar a los responsables de los hechos delictuosos con penas adecuadas a la gravedad de los delitos cometidos; así como que, en el caso de que resulten involucrados agentes del Estado, se impongan los procedimientos disciplinarios correspondientes y, en su caso, las sanciones penales a que haya lugar, adecuaciones todas estas por demás necesarias que no terminan aún de aterrizar del todo en la práctica, pues de hecho algunas de las violaciones a derechos humanos de los migrantes vienen no sólo de los agentes migratorios, sino de operativos y funcionarios de mediano y alto rango.

Es importante señalar que, además de las recomendaciones en materia de migración hechas en los diagnósticos generales y temáticos, otros varios organismos a través de sus áreas de expertiz, han reconocido los problemas que afectan a este grupo y planteado recomendaciones a México a fin de que se mejoren sus condiciones durante su estancia. ${ }^{18}$ Mención especial merecen aquí las recomendaciones hechas por el Grupo de Trabajo sobre Desapariciones Forzadas en su informe del 20 de diciembre de 2011. ${ }^{19}$ En la Adición de la Misión a México, se reconoció y criticó

18 Respecto de los problemas de las mujeres migrantes, estos se abordaron en los documentos: Relatoría Especial sobre la violencia contra la mujer, sus causas y consecuencias (2006) Informe del Comité para la Eliminación de la Discriminación contra de la Mujer (2006) Observaciones finales del Comité para la Eliminación de la Discriminación contra la Mujer (2012). Los problemas de vulnerabilidad y abuso hacia los niños, niñas y adolescentes migrantes, ha sido abordado en los dos informes de la Relatoría Especial sobre la venta de niños, la prostitución infantil y la utilización de niños en la pornografía (1998 y 2008). Respecto de las detenciones a migrantes y ejecuciones extrajudiciales, el tema ha sido abordado en tres documentos: en el Informe Grupo de Trabajo sobre la Detención Arbitraria (2002), en el documento del Comité Contra la Tortura Observaciones finales de los informes periódicos quinto y sexto combinados de México (2012), y en el Informe del Relator Especial sobre las ejecuciones extrajudiciales, sumarias o arbitrarias (2014).

19 Los dos primeros informes de este Grupo de Trabajo (18 de enero de 2002 y 21 de enero de 2004) fueron generales, es decir, incluían recomendaciones muy generales de todos los Estados miembros. En el caso de 
la violencia en el territorio nacional con motivo de la llamada guerra contra el narcotráfico, por lo que se señaló que el patrón de las desapariciones forzadas es complicado de determinar ante la diversidad de las características de las víctimas. Para el caso de los migrantes por primera vez se les reconoce como víctimas de este delito, frente al cual resultan particularmente vulnerables por su estatus de indocumentados, la falta de recursos económicos, de leyes efectivas y de programas destinados a protegerlos; pero además, se reconoce que es un problema que afecta también a los defensores de los derechos de este grupo y de periodistas que han denunciado su situación. De manera valiente el Grupo de Trabajo sostiene que el párrafo 20 que "Hasta que se realice una adecuada y completa investigación, no será posible aceptar que todos los secuestros de migrantes sean realizados exclusivamente por grupos del crimen organizado o descartar que no exista participación directa o indirecta de funcionarios públicos". Ante el escenario que se describe en el Informe, se recomendó a México, entre otras cuestiones: generar una base de datos confiable con base en las denuncias que se presenten de desaparición de personas, reconocer la desaparición forzada como delito, generar protocolos de actuación para los operativos de detención donde participen militares y garantizar a las víctimas una reparación total. ${ }^{20}$

Un breve balance de las recomendaciones expuestas permite ver que desde inicios del presente siglo la comunidad internacional tuvo conocimiento de la situación de violencia que estaba afectando a las personas migrantes $\mathrm{y}$, a través de diversos organismos, ha mostrado un destacado interés porque México genere las condiciones para asegurar a los afectados su acceso a la justicia, se investiguen los delitos y se sancione a los responsables. En términos generales, las principales interpelaciones planteadas a México ante la situación de las personas migrantes indocumentadas una vez abierto al escrutinio internacional y hasta antes de la promulgación de la ley de migración, fueron las siguientes:

- Atender el problema de violencia hacia los migrantes;

- Atender de manera pertinente la violencia hacia mujeres y niños, niñas y adolescentes migrantes;

- Suprimir la migración indocumentada como delito;

- Establecer mecanismos de acceso a la justicia para migrantes víctimas de delitos;

- Investigar los delitos y castigar a los delincuentes;

- Permitir el acceso a los órganos de justicia con independencia de situación migratoria;

México, en estos dos primeros informes no se da cuenta aún de las desapariciones forzadas para el caso de los migrantes.

20

De manera más reciente, en 2015, el Comité contra la Desaparición Forzada (2015), recomendó además, establecer lazos de cooperación con los países de origen y destino de los migrantes y con la sociedad civil, para prevenir e investigar las desapariciones de los migrantes, perseguir penalmente a los responsables y proteger los involucrados en las averiguaciones: denunciantes, peritos, testigos; así como crear mecanismos transnacionales para la búsqueda de las personas migrantes desaparecidas y la adecuada identificación de cuerpos; además de permitir que los allegados de las personas desaparecidas puedan obtener información y colaborar en las investigaciones. 
- Dar mayor difusión al marco internacional de los derechos humanos de los migrantes entre las autoridades de los tres niveles de gobierno;

- Mejorar las condiciones de aseguramiento, estancia y deportación.

Temas todos estos, hay que decirlo, mediana o simuladamente atendidos por la ley de migración y las estructuras gubernamentales.

Tabla 2: Informes generales y temáticos con recomendaciones en materia de derechos humanos de los migrantes recibidos por México antes de la promulgación de la Ley de migración de 2011

\begin{tabular}{|c|c|c|}
\hline & Órganos de Naciones Unidas & Órganos de la OEA \\
\hline 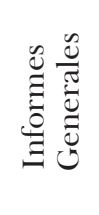 & $\begin{array}{l}2003 \text { Diagnóstico sobre la Situación } \\
\text { de los derechos humanos en México } \\
\text { del OACNU } \\
2009 \text { Informe del Grupo de Trabajo } \\
\text { sobre Examen Periódico Universal }\end{array}$ & \\
\hline 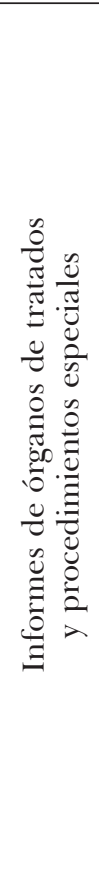 & $\begin{array}{l}\text { Informes del Comité de Protección de los } \\
\text { Derechos de Todos los Trabajadores Mi- } \\
\text { gratorios y de sus Familiares: } \\
\mathbf{2 0 0 6} \text { Examen de los Informes Pre- } \\
\text { sentados por los Estados Parte de } \\
\text { Conformidad con el Artículo } 9 \text { de la } \\
\text { Convención } \\
\mathbf{2 0 1 1} \text { Examen de los informes presen- } \\
\text { tados por los Estados parte en virtud } \\
\text { del artículo } 74 \text { de la Convención } \\
\text { Relator Especial sobre los Derechos Hu- } \\
\text { manos de los Migrantes: } \\
\text { 2002 Informe presentado por la Re- } \\
\text { latora Especial sobre los Derechos } \\
\text { Humanos de los Migrantes, Sra. Ga- } \\
\text { briela Rodríguez Pizarro, de confor- } \\
\text { midad con la resolución 2002/62 de } \\
\text { la Comisión de Derechos Humanos } \\
\text { 2009 Informe del Relator Especial } \\
\text { sobre los Derechos Humanos de los } \\
\text { Migrantes, Sr. Jorge Bustamante }\end{array}$ & $\begin{array}{l}2003 \text { Visita In Loco a México de la Relato- } \\
\text { ría Especial sobre los Derechos de los Tra- } \\
\text { bajadores Migratorios y Miembros de sus } \\
\text { Familias }\end{array}$ \\
\hline
\end{tabular}

Fuente: Elaboración propia 


\section{BREVE BALANCE DE LA REFORMA MIGRATORIA DE 2011}

La llamada reforma migratoria de mayo de 2011 incluye una nueva ley de migración, así como algunas modificaciones constitucionales, entre las que se destaca la del artículo 33; esta última, incluida como parte de las reformas en materia de derechos humanos adoptada ese mismo año.

Por su relevancia es pertinente comenzar este balance revisando el contenido del artículo 33 constitucional, el cual, en su nuevo texto prevé:

ARTíCUlo 33. Son personas extranjeras las que no posean las calidades determinadas en el artículo 30 constitucional y gozarán de los derechos humanos y garantías que reconoce esta Constitución.

El Ejecutivo de la Unión, previa audiencia, podrá expulsar del territorio nacional a personas extranjeras con fundamento en la ley, la cual regulará el procedimiento administrativo, así como el lugar y tiempo que dure la detención.

Los extranjeros no podrán de ninguna manera inmiscuirse en los asuntos políticos del país.

El artículo 33 era uno de los dispositivos constitucionales que habían permanecido sin modificaciones desde su promulgación en $1917,{ }^{21}$ y se mantuvo como un agujero para los derechos humanos dentro de la propia constitución; ${ }^{22}$ en primer lugar por lo que hace a la garantía de audiencia, la cual era negada a los extranjeros sujetos al ejercicio de la facultad prevista en este numeral, pero sobre todo, debido a la propia facultad discrecional otorgada al titular del Ejecutivo.

En cuanto a la garantía de audiencia pareciera que la nueva redacción garantiza que la expulsión no pueda realizarse sin respetarla; sin embargo, el numeral mantiene la facultad exclusiva del jefe del Poder Ejecutivo de hacer abandonar a los extranjeros el territorio nacional; y si bien es cierto que se sostiene que esta facultad ha de ejercerse conforme a la ley, con todo, esta disposición aún puede ser objeto de algunos señalamientos. En primer lugar, porque expresamente en la Constitución se indica que esta facultad se debe aplicar a través de un procedimiento administrativo, pero al mismo tiempo admite que a la persona sujeta a dicho procedimiento se le pueda detener, es decir, privarle de su libertad. En este punto el problema radica en que si la expulsión es un acto administrativo, entonces, la detención "por el tiempo que indique la ley" parece una sanción arbitraria y por lo tanto excesiva, cuando en la propia Constitución se establece que la detención administrativa será sólo por 36 horas (art. 21), que únicamente procederá

21 La versión anterior del artículo 33 señalaba: "Son extranjeros los que no posean las calidades determinadas en el art. 30. Tienen derecho a las garantías otorgadas en la sección $1^{\mathrm{a}}$ título $1^{\circ}$ de la presente Constitución, salva (sic) en todo caso la facultad que el gobierno tiene para expeler al extranjero pernicioso. Tienen obligación de contribuir para los gastos públicos, de la manera que dispongan las leyes, y de obedecer y respetar las instituciones, leyes y autoridades del país, sujetándose a los fallos y sentencias de los tribunales, sin poder intentar otros recursos, que los que las leyes conceden a los mexicanos".

22

MANUEL BECERRA RAMÍREZ, "El artículo 33 constitucional en el siglo XX", David Cienfuegos Salgado y Miguel López Olvera (Coordinadores), Estudio en homenaje a don José Fernández Ruiz, UNAM, pp. 59-82. 
mediante orden de autoridad judicial competente (art. 14) y que la prisión preventiva sólo procederá en contra de algunos delitos considerados graves (art. 18). ${ }^{23}$

El problema que surge en relación a la nueva redacción del artículo 33 constitucional es que para que se pueda aplicar de forma apegada a la ley, el primer requisito es que debe existir una ley y, desde 2011 que se reforma la Constitución a la fecha, esa ley no existe. El 21 de octubre de 2013 el titular del Ejecutivo envió a la Cámara de Senadores una iniciativa para crear la ley reglamentaria correspondiente. En esta Cámara se avaló en comisiones su aprobación en abril de 2014; la cual, de acuerdo con la información disponible en la propia página web del Senado, se aprobó en el Pleno de esa Cámara hasta diciembre de 2015; sin embargo, hasta hoy el proyecto no ha completado los demás pasos del procedimiento legislativo. Esto lleva a dejar sin normatividad de referencia y, por lo tanto, sujeto a la arbitrariedad del Ejecutivo, la forma en que se desahogue este procedimiento, y se convierte además, en una posible fuente de violencia en contra de los derechos humanos de los extranjeros, pues siguen sin conocerse cuáles son las causas legales por las cuales se podría aplicar este procedimiento; de igual modo, continúa sin quedar claro cómo debe entenderse la expresión "inmiscuirse en asuntos políticos" para los extranjeros.

Por su parte, la Ley de migración de 2011, que como ya se explicó fue largamente exigida por organismos internacionales (y por la sociedad mexicana), fue objeto de serias críticas por parte de los especialistas casi de forma inmediata a su entrada en vigor, y mucho antes de una década de haber iniciado vigencia, se han desvanecido las expectativas que se tenían a su alrededor; ya que al menos en relación a los miles de migrantes en tránsito que atraviesan México la situación parece no haber cambiado en mucho. En lo que sigue de este apartado, se analiza brevemente el contenido de la ley de migración en lo relacionado a los migrantes irregulares y, posteriormente, se analizan algunos supuestos en los que a pesar de lo expresado por la propia ley, ésta continúa siendo una fuente de violación a derechos humanos.

En la ley de migración de 2011, que a decir de la misma tiene por objeto (art. 1) regular la entrada y salida de mexicanos y extranjeros del territorio mexicano, se entiende por migrante (art. 3, frac. XVII) el "individuo que sale, transita o llega al territorio de un Estado distinto al de su residencia por cualquier tipo de motivación". ${ }^{24}$ Cuando el migrante es un extranjero que pretende ingresar

23 CUAUHTÉMOC MANUEL DIENHEIM BARRIGUETE, "El artículo 33 de la Constitución y la persecución de personas extranjeras", en Eduardo Ferrer McGRegor, José Luis Caballero Ochoa y Christian Steiner (coords.), Derechos humanos en la constitución: comentarios de jurisprudencia constitucional e interamericana II, SCJM-UnAM, México, 2013, pp. 1634-1959.

24 No está de más señalar lo criticable que resulta esta definición legal, pues incluye dentro de la categoría de los migrantes a personas como los turistas o a los asistentes a un foro académico, individuos no tienen la intención de asentarse (temporal o permanentemente) en el territorio, y que una vez concluido el periodo de esparcimiento o de realización del evento al que asisten, regresan al lugar en el que residen de forma habitual. De acuerdo con la Ley de migración estas personas se comprenden dentro de la categoría de "visitante sin permiso para realizar actividades remuneradas". 
y permanecer en territorio mexicano, esta persona puede hacerlo de forma regular dentro de alguna de las categorías previstas en la propia ley, ${ }^{25}$ de lo contrario, se puede considerar que se trata de una persona migrante irregular.

Por supuesto, el punto más álgido en la agenda migratoria del Estado mexicano es el relacionado con los migrantes irregulares en tránsito. Así, el primer acierto que debe señalarse por parte de la ley de migración es que no considera como delito el internamiento irregular de los extranjeros en el territorio mexicano sino que, tal como lo habían recomendado los organismos internacionales en múltiples ocasiones, es señalado únicamente como falta administrativa. Además, se incluyó un apartado específico para reconocer determinados derechos a las personas migrantes, lo cual no puede dejar de considerarse un avance significativo; pues aun cuando la ley ha sido criticada por no ofrecer un listado completo de derechos humanos de los migrantes irregulares, es conveniente estar atentos a lo expresado en el artículo 66, de acuerdo al cual la situación migratoria no impedirá el ejercicio de los derechos y libertades reconocidos en la Constitución, en los tratados y convenios internacionales de los que sea parte el Estado mexicano, y en la propia ley de migración.

Varias otras disposiciones resultan relevantes para el caso de los migrantes irregulares. La primera es la contenida en la segunda parte del artículo 66 donde se asegura que "el Estado mexicano garantizará el derecho a la seguridad personal de los migrantes, con independencia de su situación migratoria", declaración que, en el contexto de violencia que se ha vivido en su contra en los últimos años en las rutas por las que transitan, debe entenderse como el reconocimiento de una auténtica obligación del Estado mexicano. De igual modo, se asegura en la ley de migración que los migrantes irregulares tienen derecho a acceder a los servicios educativos y médicos, garantía esta última que incluye el servicio médico gratuito en caso de urgencia que ponga en peligro su vida.

Igualmente, se incluye una prohibición expresa en el artículo 76 de la ley de acuerdo con la cual no se podrán "realizar visitas de verificación migratoria en los lugares donde se encuentren migrantes albergados por organizaciones de la sociedad civil o personas que realicen actos humanitarios, de asistencia o protección a migrantes". Esta es una disposición relacionada con la que establece que únicamente elementos del Instituto de Migración puede solicitar a las personas que acrediten su nacionalidad o su estatus migratorio, lo cual equivale a una prohibición para que cualquier otra autoridad lleve a cabo estos actos como se daba con anterioridad a la actual ley; es también una forma de garantizar la no criminalización de la migración irregular. A su vez, esta prohibición se refuerza con lo que se estipula en el último párrafo del artículo 159 de la ley, en el cual se expresa que "no se impondrá pena a las personas (...) que por razones estrictamente humanitarias y sin buscar beneficio alguno, presten ayuda a la persona que se ha internado en el país de manera irregular, aun cuando reciban donativos o recursos para la continuación de su labor humanitaria”, pues como se señaló en el segundo

$\overline{25 \text { Cfr., artículo } 52}$ de la ley de migración. 
apartado de este trabajo, otra de las recomendaciones de organismos internacionales de derechos humanos es el proteger a la personas defensoras de derechos de los migrantes, empezando por evitar la criminalización no sólo la migración irregular, sino también la ayuda humanitaria que se les brinde. ${ }^{26}$

Ahora bien, el que la migración irregular no sea ya considerada un delito y el que se aseguren sus derechos humanos, de ninguna manera puede equivaler a una desregulación de la misma. El ingreso de manera irregular a territorio mexicano sigue estando prohibido y es considerado una falta administrativa, como se ha señalado; por lo cual, de acuerdo con la ley en comento, tras detectarse a una persona en esa situación migratoria, lo que procede es su detención administrativa (aseguramiento), y el posterior retorno o deportación a su país de origen o de residencia habitual. Con base en lo anterior, los migrantes irregulares son retenidos en una estación y sometidos al procedimiento administrativo migratorio con el fin de determinar su situación legal.

En el transcurso de su estancia en la estación migratoria y durante la resolución del procedimiento, la ley de migración reconoce a los migrantes ciertos derechos específicos; como por ejemplo el de ser informado de la ubicación exacta de la estación en la que es alojado, de las formas de regularizar su situación migratoria, así como de la posibilidad de adherirse al programa de retorno asistido si deciden no ejercer su derecho de regularizar su condición migratoria, que puede tardar semanas e incluso meses y no conlleva de manera necesaria una resolución a su favor.

Igualmente, a lo largo de su estancia y en el desarrollo del procedimiento administrativo, se les debe permitir a los migrantes el contacto con la representación consular que les corresponda, y tienen derecho a recibir asistencia jurídica para que les asesore en la presentación y desahogo de las pruebas pertinentes, así como para manifestar lo que a su derecho convenga. Se garantiza también la posibilidad de que las personas que han sido víctimas, ofendidos o testigos de un delito en territorio mexicano, puedan solicitar una condición de estancia como visitante por razones humanitarias, la cual les da el derecho de permanecer en México en tanto se resuelve el proceso correspondiente.

De acuerdo con la ley de migración en ningún caso se podrán habilitar como estaciones migratorias los centros de encarcelamiento o de reclusión preventiva o de ejecución de sentencias (art. 106). En otras palabras, las estaciones migratorias deben ser edificios especialmente dedicados al fin de alojar migrantes en tanto se resuelve legalmente sobre su situación legal. Dichas estaciones deben contar con servicios de asistencia médica, psicológica y jurídica; de igual modo, en dichos lugares se debe proporcionar la alimentación adecuada a los migrantes. Las áreas de la estación migratoria en que se hallen hombres y mujeres deberán estar debidamente separadas; y en su caso los niños, niñas, adolescentes, mujeres

26 En su informe temático más reciente en la materia, Los desafios de la migración y los albergues como oasis, la Comisión Nacional de los Derechos Humanos además de dar a conocer las dificultades que enfrentan los migrantes en su tránsito por México, reconoce la importancia que los albergues y casas de migrantes tienen en la protección y defensa de sus derechos. 
embarazadas y personas de la tercera edad, deberán recibir la asistencia especial que su condición de vulnerabilidad amerite.

Para el caso específico de niños, niñas y adolescentes, la ley de migración exige que sea respetado el principio de unidad familiar, por lo cual se promoverá que permanezcan en los mismos espacios que sus padres, siempre que sea posible; y en el caso en que se trate de menores no acompañados, serán alojados en lugares especiales. De acuerdo con la ley, la autoridad de la materia tiene 15 días para determinar si la situación migratoria es regular; en caso contrario, se prevén algunos supuestos que podrían prolongar este periodo, los cuales se relacionan con dificultades relativas a demostrar la identidad del migrante o a la imposibilidad física para que pueda realizar el viaje de deportación. No obstante, se estipula que el lapso que un migrante puede permanecer en una estación migratoria es hasta de 60 días; transcurrido este tiempo se otorgará al migrante un permiso como visitante temporal, con la posibilidad de realizar actividades económicas remuneradas, con el fin de que pueda permanecer en el país en tanto se determina su situación migratoria.

Después de conocer algunas de las disposiciones contenidas en la ley de migración (relacionadas en particular con la migración irregular), es momento de exponer algunas consideraciones al respecto. En el largo proemio contenido en los artículos primero y segundo de la propia ley se asegura que el principio cardinal que la guía es la salvaguarda de los derechos humanos de los migrantes nacionales y extranjeros; y que por lo tanto, esos derechos son la guía que debe seguir la política migratoria que adopte el Estado mexicano. No obstante dicha declaración, esta ley bien pronto se hizo objeto de algunas críticas en las que se señalaban las continuidades respecto de la anterior normatividad contenida en la ley general de población, que representan menoscabo a los derechos humanos reconocidos en la Constitución y en los tratados internacionales. ${ }^{27}$

Entre las críticas más señaladas están las ambigüedades contenidas en este cuerpo legal, las cuales se traducen en inseguridad jurídica para los migrantes. Un ejemplo es lo señalado en su artículo 3, donde se lee que "La libertad de toda persona para ingresar, permanecer, transitar y salir del territorio nacional tendrá las limitaciones establecidas en la Constitución, los tratados y convenios internacionales de los cuales sea parte el Estado mexicano, esta ley y demás disposiciones jurídicas aplicables". Tal como señala Castilla ${ }^{28}$ la expresión "y las demás disposiciones jurídicas aplicables" abre la puerta para que estas limitaciones puedan encontrarse en normativas de menor rango jurídico que las leyes, como lo son los reglamentos o las simples circulares, situación que es contraria a la exigencia constitucional y convencional de que las libertades únicamente pueden ser restringidas por leyes emanadas del Legislativo, lo cual convierte a esta disposición en una posible fuente de violencia para los derechos humanos de los migrantes, pues los expone a la arbitrariedad de las autoridades migratorias. Sobre todo

\footnotetext{
27 KARLOS A. CASTILLA JUÁREZ, "Ley de Migración mexicana: Algunas de sus inconstitucionalidades", Revista Migración y Desarrollo, Vol.12, no.23, Zacatecas, México, 2014, pp.154-155.

28

KARLOS A. CASTILLA JUÁREZ, "Ley de Migración mexicana... p. 168.
} 
porque en la práctica a los funcionarios administrativos se les exige preferir la aplicación de sus manuales, circulares internas y reglamentos, antes incluso que las leyes emanadas del legislativo. Otro ejemplo más es la disposición contenida en el artículo 40 conforme a la cual al momento de definir los requisitos para que expidan las visas se remite al reglamento, siendo que éste es un cuerpo normativo de menor jerarquía y que no es expedido por un órgano legislativo; y la cuestión se torna más grave cuando se hace notar que hubo de pasar más de un año para que se emitiera dicho reglamento. ${ }^{29}$

Un señalamiento más que debe hacerse a la ley de migración es con relación al ejercicio del derecho de acceso a la justicia que pueden hacer valer los migrantes cuando han sido víctimas de delito. Hay que partir de la detención en estaciones migratorias, eufemísticamente llamada "alojamiento". Como ya se hizo notar líneas arriba, ingresar al país de forma irregular no es sino una falta administrativa, por lo cual la detención por 15 días o más (hasta 60) conforme al artículo 111 de la ley de migración, resulta por sí misma violatoria de derecho fundamentales como la libertad física y todo lo que ella implica, ya que por una falta administrativa la privación de la libertad no puede exceder las 36 horas según las disposiciones constitucionales.

Sin embargo, de acuerdo con el propio artículo 111 (fracción V), una de las razones por las cuales el periodo de 15 días se puede extender hasta por 60, es "Que se haya interpuesto un recurso administrativo o judicial en que se reclamen cuestiones inherentes a su situación migratoria en territorio nacional; o se haya interpuesto un juicio de amparo (...)"; es decir, que si un migrante hace uso de su derecho de acceso a la justicia y acude ante alguna autoridad exigiendo sus derechos, por esa razón se le puede hacer permanecer por más tiempo en las estaciones migratorias. Como se puede observar, es una medida que desalienta el ejercicio del derecho señalado, pero que además criminaliza a las personas migrantes al obligarles a permanecer en las instalaciones de reclusión respectivas en tanto se resuelven los recursos legales intentados.

Otra cuestión contemplada en la ley que resulta en detrimento del derecho de acceso a la justicia de los migrantes es que se otorgan al Instituto Nacional de Migración facultades que son exclusivas de los ministerios públicos. Es el caso del procedimiento para la detección, identificación y atención de extranjeros víctimas del delito previsto en el artículo 113 de la ley, el cual de hecho, se limita a disponer que dicho procedimiento será regulado en el reglamento de la propia ley, y que ha quedado establecido en los artículos 178 a 184 del mismo. Básicamente lo que se prevé es que cuando personal del Instituto Nacional de Migración crea estar ante un migrante que pudo haber sido víctima de delito se le debe realizar una serie de entrevistas con el objetivo de determinar si efectivamente se puede presumir la existencia del delito para que, en su caso, se canalice a los afectados

29 La ley fue publicada el 25 de mayo de 2011, y su reglamento hasta el 28 de septiembre de 2012, es decir, mucho después de pasados los 180 días señalados como periodo máximo para su expedición según el artículo tercero transitorio de la ley. 
(si así lo desean) ante las instancias correspondiente, esto es, el ministerio público o fiscalía que corresponda. De este modo, se instituye al INM como una autoridad calificadora del delito, previamente a la intervención de los funcionarios ministeriales; hecho este que lesiona gravemente el ejercicio del derecho de acceso a la justicia, ya que en la práctica, conforme a diversas entrevistas sostenidas con funcionarios ministeriales, esta facultad del Instituto es utilizada como "filtro" para descartar a quienes únicamente "fingen" haber sido víctimas de delito con el fin de obtener la condición de estancia por razones humanitarias prevista en la propia ley. Evidentemente de esta manera la autoridad migratoria se sustituye al ministerio público (y fiscalías especializadas) como autoridad calificadora del delito; y como se puede colegir, pueden resultan serias lesiones a los derechos de las personas migrantes víctimas de delito.

Es importante comentar aquí que desde su publicación en 2011 a la fecha, la ley de migración ha tenido ocho reformas en varios de sus numerales, no todas con la misma trascendencia; sólo la primera reforma de 2013 al artículo 112 se relaciona de manera indirecta con la protección de derechos de las personas migrantes, en este caso, de las niñas, niños y adolescentes migrantes. En ella, se amplían los mecanismos de protección de los menores migrantes no acompañados y se estable que, para el caso de su repatriación, el procedimiento correrá a cargo no del Instituto Nacional de Migración sino del Sistema Nacional para el Desarrollo Integral de la Familia. Esta nueva forma de gestionar la migración infantil es en particular relevante considerando la vulnerabilidad de los menores y la especialización que en su trato y atención en general hacia la infancia tienen los integrantes de tal Sistema, y no así los del Instituto. Cierto que es una reforma en la gestión de la migración, mas repercute de manera inmediata y positiva en la atención y protección de la persona y derechos de los menores migrantes.

Una reforma relativa al fortalecimiento institucional fue la publicada en el Diario Oficial el 25 de junio de 2018, a través de la cual se modifica la fracción I del artículo 30. En dicho artículo se plasman las atribuciones que, como autoridad auxiliar en materia migratoria, corresponde llevar a cabo al Instituto Nacional de las Mujeres; la reforma consistió en especificar su facultad para realizar acciones, de manera coordinada con el Instituto Nacional de Migración, tendientes a la prevención de la violencia contra las mujeres migrantes ya que, dada su condición de tales, los tipos y modos de violencia son particulares de su condición de género e incrementa sus niveles de vulnerabilidad y riesgo durante su tránsito como migrantes irregulares.

Las autoridades que con más frecuencia son señaladas como responsables de cometer abusos o violentar los derechos de los migrantes son los propios agentes migratorios; esto, desde luego, está relacionado con el hecho de que son ellos las principales autoridades con quienes los migrantes tienen contacto con más frecuencia, pero también con problemas que se han arraigado al interior del Instituto de Migración y que están relacionados con los amplios márgenes de discrecionalidad permitidos por la normatividad anterior; en otras palabras, la realidad es que las malas prácticas no siempre pueden ser erradicadas por el mero cambio 
de la ley. Así, en aras de mejorar el desempeño de los agentes del Instituto Nacional de Migración, pero también de ofrecer igualdad en el ingreso, permanencia y desarrollo del servicio, se instituye el servicio profesional de carrera introduciéndolo en 2013 en los artículos 3 y 25 de la ley.

Las otras cinco modificaciones hechas a la ley de migración desde su promulgación en 2011 han sido cuestiones no relativas con los derechos de los migrantes, sino más bien con aspectos de técnica legislativa, como aclarar un concepto o afinar la redacción de un artículo. ${ }^{30}$

Para cerrar este apartado se debe decir que aún con la nueva ley y pese a las reformas que esta ha sufrido en los últimos años, la exigencia principal de las organizaciones no gubernamentales, que es el paso libre o eliminación de la visa de entrada a México, sigue siendo sólo una aspiración.

\section{LOS PROGRAMAS PARA LA GOBERNANZA DE LAS MIGRACIONES EN EL PERIODO 2012-2018}

La administración gubernamental encabezada por el presidente Enrique Peña Nieto inició con un nuevo marco regulatorio de la migración conformado por la propia reforma constitucional en materia de derechos humanos, la nueva ley de migración (ambas de 2011), y el reglamento de esta última publicado en 2012. Esto pudo representar la posibilidad de instrumentar una gestión o "gobernanza migratoria" más respetuosa de los derechos humanos de las personas migrantes; sin embargo esta oportunidad se dejó pasar, pues lo que en realidad se vivió fueron seis años de acciones reactivas y desarticuladas, a la usanza de los gobiernos anteriores.

En abril de 2014 se dio a conocer a través del Diario Oficial de la Federación el Programa Especial de Migración 2014-2018 (PEM), el cual estaba trazado bajo cinco objetivos, 26 estrategias y 195 líneas de acción. Con su instrumentación se buscaba, según su propio contenido, orientar la política migratoria mexicana hacia la gobernanza de las migraciones, esto es:

... hacia un esquema de tipo relacional que se basa en la interlocución coordinada entre los diversos actores involucrados (públicos, privados, organizados, no

30 En la reforma a los artículos 3-II y 55 segundo párrafo, del 30 de octubre de 2014, se elimina la descripción asilado y se remite a la ley de la relativa; se reconocen también los tratados internacionales en la materia para efectos de la preservación de la unidad familiar. El 21 de abril de 2016 es publicada la reforma al artículo 48 donde se le adiciona la fracción VI para establecer como causal de prohibición de la salida del territorio nacional el incumplir por más de sesenta días con la obligación alimentaria. Por su parte, en la reforma publicada el 19 de mayo de 2017 se reforma la fracción III del artículo 52 para ampliar a siete días máximo el plazo autorizado para permanecer en territorio nacional al visitante regional, anteriormente restringido a sólo tres días.

El 9 de noviembre de 2017, los artículos 29, primer párrafo, y 112, fracciones I y VI, tercer párrafo, son reformados para actualizar la terminología del Distrito Federal por la de la Ciudad de México. Finalmente, en la reforma más reciente, publicada el 12 de julio de 2018, se hace una reforma de técnica legislativa donde se corrige que "El Instituto resolverá la situación regular de los extranjeros presentados en un plazo no mayor de 15 días hábiles, contados a partir de su presentación" por simplemente que "resolverá la situación de los extranjeros". 
organizados, individuales o colectivos). Esto no sólo con el propósito de fortalecer la atención integral del fenómeno en un ambiente de responsabilidad nacional e internacional, sino también con el fin de garantizar el debido respeto a los derechos humanos de las personas migrantes (PEM, 2013, 27).

En general, el PEM estuvo encauzado a la atención de migrantes mexicanos y sus familias, ya sea que se encontraran fuera de México o en retornando al territorio nacional; la planeación de una adecuada atención hacia la migración indocumentada fue escasa y se focalizó básicamente en los problemas de violencia y de acceso a la justicia.

En el objetivo 1 del PEM se estableció "Fomentar una cultura de la legalidad, de derechos humanos y de valoración de la migración”, esto, a través de la adecuación del marco normativa de conformidad con lo que la realidad demandase, y del fortalecimiento de la capacidad institucional del Estado para "potenciar los beneficios de la migración y reducir sus costos". Al respecto, se puede afirmar que el marco normativo para la gestión de la migración con el que se concluye este periodo no dista mucho de aquel con el que inició, a pesar de las ocho reformas hechas a la ley de migración ya comentadas en líneas anteriores.

Como objetivo 2 del PEM se plantó "incorporar el tema migratorio en las estrategias de desarrollo regional y local" a través de acciones más orientadas hacia la migración de connacionales, como lo es el fortalecimiento de los vínculos entre migrantes mexicanos y sus comunidades de origen; así como el aprovechamiento productivo de las remesas.

Por su parte, el objetivo 3 del Programa perseguía "consolidar una gestión migratoria eficaz, fundamentada en criterios de facilitación, corresponsabilidad internacional, seguridad fronteriza y seguridad humana". Este objetivo, aunque en sí mismo es bastante amplio, lo relativo a los extranjeros se orienta más hacia los sectores turísticos y de negocios, es decir, migración regular, a efectos de facilitar y agilizar su ingreso y estancia en el país; en lo relativo a la migración irregular, se contemplan como acciones el establecimiento de protocolos y acciones afirmativas para facilitar a las personas en condiciones de vulnerabilidad la obtención de documentos y sus procesos de regularización, así como a impulsar acciones afirmativas respecto de los menores y mujeres migrantes. En lo relativo al crecimiento institucional se plantean estrategias como la mejora y modernización de la infraestructura propia del Instituto Nacional de Migración para la atención de los usuarios (lugares destinados al tránsito internacional de personas, oficinas de trámites, estaciones migratorias y estancias), y la profesionalización de los agentes migratorios de servicio interno y exterior a través del fomento del servicio profesional de carrera, de cursos de capacitación legal y sensibilización, del aprendizaje de idiomas, entre otros. Respecto de este objetivo hemos visto que, la ley de migración en efecto se reformó para alcanzarlo; es decir, las adecuaciones normativas sí se dieron.

En relación al objetivo 4 que perseguía el favorecimiento de "los procesos de integración y reintegración de las personas migrantes y sus familiares", en las 
seis estrategias y las 40 acciones que contempla, únicamente dos de ellas se refieren a la migración indocumentada para el caso de brindar asistencia médica, haciendo especial énfasis a los casos de mujeres que hayan sido víctimas de violencia sexual o estén realizando su tránsito embarazadas. Por lo demás, las estrategias y acciones están orientadas a la atención de migrantes retorno y sus familias, aunque plantea dos o tres acciones dirigidas a la población solicitante de asilo, sujeta a protección internacional y refugiada.

Finalmente, en el objetivo 5, el único expresamente dirigido a la protección de la migración indocumentada en tránsito, se buscaba "fortalecer el acceso a la justicia y seguridad de las personas migrantes, sus familiares y quienes defienden sus derechos." En la justificación de este objetivo se reconocen los problemas de violencia que afectan a este tipo de flujos, tanto por parte de los grupos delictivos, como de las propias autoridades; de ahí el que señale que:

... la política migratoria integral del Estado mexicano debe adoptar medidas de prevención, persecución y sanción de las infracciones y delitos contra las personas migrantes, sus familiares, sus defensoras y defensores, así como fortalecer acciones en materia de acceso y procuración de justicia.

Con este objetivo se busca prevenir y reducir los delitos y la violencia ejercida contra este grupo de población; fortalecer los mecanismos y procesos de investigación y sanción; aumentar la confianza en las instituciones y profesionalizar a los servidores públicos que atienden el tema migratorio; facilitar y fomentar la denuncia; dar certidumbre en los procesos judiciales; así como garantizar el ejercicio pleno de derechos, particularmente en estaciones migratorias, estancias, albergues, refugios y casas de migrantes.

Para el desarrollo de este objetivo se contemplaron cuatro estrategias y cuarenta acciones concretas, de entre las cuales, quizá la más notoria sea la creación de fiscalías especializadas para la atención de migrantes víctimas del delito, lo cual fue una recomendación reiterada al Estado mexicano por parte de organismos internacionales de derechos humanos, como hemos visto ya; debido a esto último es que las primeras fiscalías se crean con anterioridad a la promulgación de la ley de migración y, desde luego, de la elaboración del PEM.

Hoy, los cuatro estados fronterizos del sur cuentan con este tipo de órganos: Chiapas ha instalado desde 2008 a la fecha ocho de ellos en los municipios de Tapachula, Suchiate, Huixtla, Arriaga, Frontera Comalapa, Comitán de Domínguez, Tuxtla Gutiérrez y Palenque; Tabasco instaló una fiscalía en Tenosique hasta 2014; Quintana Roo y Campeche, aunque con menos presencia de este flujo, se suman en 2015 a esta estrategia creando estos órganos en Ciudad Candelaria y Subteniente López, respectivamente. En la frontera norte, por su parte, sólo dos estados han instalado este tipo de órganos: Tamaulipas (desde 2013) cuenta hoy con cinco de ellos ubicados en Ciudad Victoria, Tampico, Reynosa, Matamoros y Nuevo Laredo; y Coahuila desde 2014 tiene una Dirección general de alto impacto y delitos cometidos en agravio a migrantes. Las únicas dos entidades no fronterizas que cuentan con este tipo de órganos son Veracruz y Oaxaca. En Veracruz, la primera fiscalía se instala en 2011 en la capital del estado, Xalapa; dos 
años después, en 2013, se apertura una auxiliar en Acayucan, ciudad ubicada en uno de los corredores migratorios señalados como de los más violentos en la ruta del Golfo; la fiscalía de Oaxaca se localiza desde 2012 en Ciudad Ixtepec, municipio donde se llevó a cabo el primer secuestro masivo de migrantes denunciado en diciembre de 2006.

Los resultados de todos estos órganos especializados no son uniformes, varían de una entidad a otra; aunque, desde luego, la mayoría de ellos reproducen en automático los vicios propios de los sistemas de procuración de justicia en México que conllevan por lo general a una doble victimización de los denunciantes. Baste aquí con señalar que, para el caso específico de Veracruz, desde 2011 que se instala la primera fiscalía y se empiezan a recibir todo tipo de denuncias por parte de las personas migrantes, sólo se ha logrado obtener una única sentencia condenatoria sancionando con una pena de tres años a una persona encontrada culpable del delito de robo. ${ }^{31}$

Si bien es necesario tener presente la idea de soberanía de las entidades federativas, no se puede afirmar que las fiscalías estatales estén trabajando bajo un esquema de coordinación en atención al Plan Nacional de Migración; por el contrario, se trata más bien de acciones prácticamente aisladas de cada entidad, donde algunas incluso han decidido no implementarlas pese a los elevados niveles de violencia hacia los migrantes que también se reportan en sus territorios, como son los casos de Jalisco y Puebla.

Además del Programa Nacional de Migración, durante este periodo gubernamental se creó el Plan Frontera Sur (PFS), anunciado en el decreto que creó el órgano encargado de instrumentarlo, la Coordinación para la Atención Integral de la Migración en la Frontera Sur. En principio, el PFS se supone fue diseñado para atender el tránsito migratorio en esa frontera, brindar mayor protección a los derechos humanos de los migrantes, fomentar la cohesión social y aumentar la seguridad fronteriza mediante una mayor vigilancia de la región y del control del crimen organizado. No obstante, desde su creación el PFS fue objeto de múltiples críticas al no haber sido trazado mediante un proceso de consulta con las organizaciones defensoras de derechos humanos ni con la academia especializada. Por otra parte, es considerado una acción en paralelo a las detenciones de menores y de familias enteras que estaba llevando a cabo el gobierno estadounidense. Para la operatividad del PFS se destinaron 102 millones de pesos, sin embargo, las acciones implementadas consistieron básicamente en el incremento del número de agentes migratorios en esa frontera y en el número de operativos que fueron desplegados para detener, diagnosticar y deportar a los migrantes indocumentados;32 quizá de ahí el elevado aumento de los asegurados entre 2014 y 2015 (Tabla 1). Apenas

31 Para un análisis a mayor profundidad del caso de Veracruz y de los aspectos generales de la cuestión, puede consultarse el trabajo de JUANA LUSIA RÍOS ZAMUDIO “(In)capacidades institucionales en la procuración de justicia para migrantes en tránsito por Veracruz”, en Alberto Olvera Rivera, La justicia denegada. Ensayos sobre acceso a la justicia en Veracruz, Universidad Veracruzana, México, 2018.

32 ADAM ISACSON, MAUREEN MEYER Y HANNAH SMITH, Informe de Investigación La frontera sur de México. Seguridad, migración centroamericana y políticas estadounidenses, WOLA, México, 2017. 
un año después de su creación, la Coordinación fue desaparecida y sus funciones trasladadas a la Unidad de Política Migratoria también de la Secretaría de Gobernación; la supresión de este órgano fue hecha a propuesta de la Secretaría de Hacienda señalando problemas presupuestales, sin embargo, lo que deja claro es el poco interés por parte del titular del Ejecutivo para desplegar acciones concretas y sostenibles a fin de atender de manera integral a la migración indocumentada con estricto apego a los derechos humanos, tal como lo establece la ley de migración. Lo anterior hace evidente que la gobernanza de la migración en México sigue siendo más un discurso que una directa ocupación de la autoridades o, por lo menos, una franca aspiración.

Se ha querido cerrar este apartado señalando que, aunque sea de manera aislada y tangencial, son ya varias las entidades federativas que se han dado a la tarea de brindar diversos tipos de atención a la migración indocumentada que transita o se asienta en sus territorios; en algunas de ellas inclusive se han promulgado leyes de atención a personas migrantes, con las que, desde luego, no buscan regular la entrada y salida de sus territorios, sino atender algunas de las necesidades jurídicas, sociales y asistenciales de los migrantes. Entre las entidades que cuentan hoy con esa tipo de ley están Baja California, Durango, Guanajuato, Hidalgo, Sonora, Estado de México, Oaxaca, Tlaxcala, Chihuahua, Ciudad de México, Michoacán y Veracruz.

Por otra parte, las 32 entidades del país cuentan desde hace tiempo con direcciones o institutos e incluso secretarías o subsecretarías de migración. Estos órganos, creados generalmente con la intención de brindar cierto tipo de atención a sus paisanos migrantes en el extranjero son los que están encargados de instrumentar lo contenido en las leyes migratorias de las entidades. No obstante, la mayoría de estos organismos no brinda el apoyo de forma directa a los migrantes indocumentados, sino a través de los albergues y casas de migrantes, a las que dotan de algunos insumos para que continúen con su labor de asistencia humanitaria. Sin embargo, varias de las leyes de atención a migrantes contemplan para estos órganos obligaciones específicas que poco a poco deberán empezar a cubrir, como por ejemplo desarrollar programas específicos de apoyo a migrantes en tránsito, así como actividades de asistencia legal y canalización e incluso vinculación con las agencias consulares, para cuando han sufrido algún accidente o han sido víctimas del delito. También se contempla la posibilidad de facilitar una matrícula o identificación oficial, que si bien no regula la situación migratoria de los extranjeros irregulares en México, sí los identifica y les da ciertas garantías legales.

A todo esto, se debe señalar que las actividades que se están llevando a cabo en las entidades federativas no están siendo coordinadas o amalgamadas para un trabajo interinstitucional. Corresponde a la federación realizar ese estrechamiento entre los diversos órganos para la mejor atención de las personas migrantes. Ese trabajo de coordinación no se realizó en el periodo gubernamental que concluye este año. Habrá que estar atentos a la manera en que la administración que inicia decide atender a este flujo; si decide tomar acciones planificadas, sostenidas e 
interinstitucionales con estricto apego a los derechos humanos de los migrantes, o si como ha sucedido hasta ahora, opera también a través de acciones emergentes según lo que la ocasión demande.

\section{CONSIDERACIONES FINALES}

Como se ha podido apreciar en las líneas que preceden, los cambios normativos a favor de los migrantes han sido numerosos pero no lo suficientemente profundos como para garantizar derechos básicos a los migrantes irregulares. No obstante, el cuadro se completa cuando se analizan las políticas migratorias implementadas en los últimos años, las cuales, lejos de proponerse acciones tendientes a la realización de los compromisos del Estado mexicano en la materia, se han concentrado en el fortalecimiento del control migratorio, rubro en el que por cierto, tampoco han sido exitosas.

A través de la llamada reforma migratoria se modificaron varias disposiciones constitucionales y se promulgó una nueva ley y un nuevo reglamento que regulan de manera exclusiva la materia migratoria; sin embargo, las necesidades jurídicas de los migrantes están aún lejos de ser satisfechas por estas nuevas disposiciones. Si bien, contar con disposiciones normativas que respalden los derechos y pretensiones de las personas es importante, lo cierto es que no es suficiente para asegurarles un ejercicio efectivo de los mismos, y esta posibilidad se difumina aún más cuando dicha legislación no es suficiente. ${ }^{33}$

Lo aquí expuesto ha permitido observar la diversidad de actores (principalmente internacionales) que estuvieron impulsando el cambio legislativo a favor de los migrantes, y es poco probable que sin esa colaboración se hubiera visibilizado el tema y se concretaran las reformas legales de 2011. La promulgación de la ley de migración, sin embargo, no significa que el trabajo de estos organismos defensores de los derechos humanos de los migrantes esté concluido. Después de 2011 México ha recibido nuevos informes en lo que se le insiste en la importancia de atender los problemas de los migrantes en su tránsito por nuestro territorio. ${ }^{34} \mathrm{La}$ realidad reciente parece estar desbordando de nueva cuenta el marco legal de la materia; las oleadas de migrantes que se han vivido en 2018 han tensionado la realidad migratoria de una forma que no se tenía prevista al momento de adoptar la ley en 2011. Todo parece indicar que el marco legal representado por esta ley no ha sido suficiente para gestionar las dimensiones y complejidades gestados en torno a la migración en tránsito; a las necesidades sociales, de asistencia, de orientación y protección de los diversos subgrupos que integran este flujo: mujeres, menores, indígenas, refugiados, asilados, en fin.

33 CHARLES EPP, La revolución de los derechos. Abogados, activistas y cortes supremas en perspectiva comparada, Siglo XXI, Argentina, 2013.

34

En 2013 recibe el Segundo Informe del Grupo de Trabajo sobre Examen Periódico Universal NNUU y el informe Derechos humanos de los migrantes y otras personas en el contexto de movilidad humana de la Comisión Interamericana de Derechos Humanos, y en 2015 el informe general titulado Situación de los derechos humanos en México también de la Comisión Interamericana. 
Se ha hecho evidente que ante este escenario el principal criterio de gestión ha sido la discrecionalidad del Ejecutivo, pues la ley en sus términos actuales no ha logrado ser un instrumento a partir del cual se promoviera una migración ordenada, o se garantizaran derechos básicos a las personas que participan de estas travesías. Dos ejemplos más de esta discrecionalidad y de lo marginal que ha resultado la nueva normatividad migratoria durante este periodo gubernamental son el Programa Especial de Migración y el Programa Frontera Sur, con escasos o nulos resultados en materia de atención a migrantes en tránsito.

En este último aspecto, las entidades federativas parecen estar siendo más receptivas al asumir - algunas de ellas - el reto de proporcionar, por efecto de leyes de alcance local, mejores condiciones para el ejercicio de derechos, no sólo para los paisanos migrantes en el extranjero, sino también para los migrantes irregulares (incluidos los migrantes en tránsito). Esto no significa que las entidades federativas estén arrogándose facultades de control migratorio, las cuales son exclusivas de la federación; sino que se está aceptando el hecho innegable de que en su día a día los migrantes, al igual que cualquier otra persona, llevan a cabo actividades que salen de la esfera de lo propiamente migratorio. Es por ello que resulta fundamental el papel que están adoptando las entidades federativas en la atención a migrantes irregulares, aun cuando, como ya se comentó, estos esfuerzos se lleven a cabo por el momento de manera desarticulada, que hace necesario que la federación se asuma como el actor que orqueste esa coordinación, lo que será parte de dar cumplimiento a las obligaciones internacionales contraídas en materia de atención y protección de los migrantes por parte del Estado mexicano.

\section{FUENTES}

ARMIJO CANTO, Natalia; BENÍTEZ MANAUT, Raúl y HRISTOULAS, Athanasios "Las maras en triángulo de seguridad Centroamérica-MéxicoEstados Unidos”, en Carlos Barrachina (coord.), Democracias en transición en Honduras y Nicaragua. Gobernabilidad, seguridad y defensa, Universidad de Quintana Roo-Plaza y Valdés, México, 2010, pp. 339-369.

BARRACHINA, Carlos; RAMOS, Jimmy y MONJARAZ, Alejandro, “Quintana Roo en el contexto migratorio mexicano" en Enrique Baltar, María da Gloria Marroni y Daniel Villafuerte (coords.), Viejas y nuevas migraciones forzadas en el sur de México, Centroamérica y el Caribe, UQROO, México, pp. 269-314.

BECERRA RAMÍREZ, Manuel, "El artículo 33 constitucional en el siglo XX”, en David Cienfuegos Salgado y Miguel López Olvera (Coordinadores), Estudio en homenaje a don José Fernández Ruiz, UNAM, pp. 59-82.

CASTILlA JUÁREZ, Karlos Artemio, "Ley de Migración mexicana: Algunas de sus inconstitucionalidades", Revista Migración y Desarrollo, vol. 12, no.23, Zacatecas, México, 2014.

CASTILLO, Manuel Ángel, "Las políticas hacia la migración centroamericana en países de origen, de destino y de tránsito", Revista Papeles de población, vol. 6, no. 24, abril-junio, UAEM, México, 2000. 
COMISIÓN NACIONAL DE LOS DERECHOS HUMANOS, Los desafios de la migración y los albergues como oasis, CNDH, México, 2018.

, Informe Especial sobre los Casos de Secuestro en Contra de Migrantes, CNDH, México, 2011.

, Informe Especial sobre los Casos de Secuestro en Contra de Migrantes, CNDH, México, 2009.

DIENHEIM BARRIGUETE, Cuauhtémoc Manuel, "El artículo 33 de la Constitución y la persecución de personas extranjeras", en Eduardo Ferrer McGRegor, José Luis Caballero Ochoa y Christian Steiner (coordinadores), Derechos humanos en la constitución: comentarios de jurisprudencia constitucional e interamericana II, SCJM-UNAM, México, 2013, pp. 1634-1959.

EPP, Charles, La revolución de los derechos. Abogados, activistas y cortes supremas en perspectiva comparada, Siglo XXI, Argentina, 2013.

GARCÍA AGUILAR, María del Carmen, "Violencia y ética. A propósito de la inmigración irregular y los derechos humanos en la frontera sur de México", en Daniel Villafuerte Solís y María del Carmen García Aguilar (coordinadores), Migración, seguridad, violencia y derechos humanos. Lecturas desde el sur, Miguel Ángel Porrúa, México, pp. 79-125.

HERRERA-LASSO, Luis y B. ARTOLA, Juan, "Migración y seguridad: dilemas e interrogantes" en Natalia Armijo, Migración y seguridad: nuevo desafío en México, CASEDE, México, 2011, págs. 11-33.

HERNÁNDEZ VALENCIA, Javier y ANAYA MUÑOZ, Alejandro (compiladores), "Presentación", Recomendaciones internacionales a México en materia de derechos humanos. Contrastes con la situación del país, ACNUM, México, pp. 7-8.

ISACSON, Adam; MEYER, Maureen y SMITH, Hannah, Informe de Investigación La frontera sur de México. Seguridad, migración centroamericana y politicas estadounidenses, WOLA, México, 2017.

MARRONI, María Da Gloria, "Latinoamérica en la geografía mundial: nuestro sur en el norte", en Daniel Villafuerte Solís y María del Carmen García Aguilar (coordinadores), Migración, seguridad, violencia y derechos humanos. Lecturas desde el sur, Miguel Ángel Porrúa, México, pp. 51-77.

RÍOS ZAMUDIO, Juana Luisa, "(In)capacidades institucionales en la procuración de justicia para migrantes en tránsito por Veracruz", en Alberto Olvera Rivera, La justicia denegada. Ensayos sobre acceso a la justicia en Veracruz, Universidad Veracruzana, México, 2018, pp. 67-119.

RODRÍGUEZ CHÁVEZ, Ernesto; BERUMEN SANDOVAL, Salvador y RAMOS, Luis Felipe, "Migración centroamericana de tránsito irregular por México. Estimaciones y características generales", Apuntes sobre migración, no. 2, Centro de Estudios Migratorios del INM, México, 2011.

RUIZ MARRUJO, Olivia, "Riesgo, migración y espacios fronterizos, una reflexión", Estudios demográficos y urbanos, vol. 16, no. 2, mayo-junio, El Colegio de México, México, 2001, pp. 257-284. 
RUIZ MARRUJO, Olivia "Los riesgos de cruzar. La migración centroamericana en la frontera México-Guatemala", Frontera Norte, vol. 13, no. 25, enerojunio, El Colegio de la Frontera Norte, México, 2001.

VILLAFUERTE SOLÍS, Daniel, "Políticas de seguridad y migración transnacional en la frontera sur de México", en Daniel Villafuerte Solís y María del Carmen García Aguilar (coordinadores), Migración, seguridad, violencia y derechos humanos. Lecturas desde el sur, Miguel Ángel Porrúa, México, pp. 167-207.

YANKELEVICH, Pablo, ¿Deseables o indeseables? Las fronteras de la extranjería en el México posrevolucionario, Bonilla Artigas Editores, México, 2011. 